\title{
EVALUATION OF IMF PROGRAMMES ON EMPLOYMENT IN THE EU
}

\author{
Gurgen OHANYAN - Armenia ANDRONICEANU
}

(Received: 22 March 2016; revision received: 20 May 2016;

accepted: 9 July 2016)

\begin{abstract}
The International Monetary Fund (IMF) has undergone notable changes by starting collaboration with the European Union (EU). Hence, this paper seeks to estimate the effects of IMF programmes on employment, with data from the EU-28 between 1993 and 2013. In order to control for selection on observable and unobservable variables, the study employs Propensity Score Matching in combination with the Differences-in-Difference estimator. Next, the robustness of the findings is checked by applying four different matching algorithms. Our paper concludes that employment decreases once a country resorts to the IMF, and this impact is still measurable after two years of programme initiation.
\end{abstract}

Keywords: European Union, IMF programmes, propensity score matching, conditional lending, employment

JEL classification indices: C21, E24, F55

Gurgen Ohanyan, corresponding author. $\mathrm{PhD}$ candidate at the Bucharest University of Economic Studies, Bucharest. E-mail: gurgen.ohanyan@man.ase.ro

Armenia Androniceanu, Professor at the Bucharest University of Economic Studies.

E-mail: armenia.androniceanu@man.ase.ro 


\section{INTRODUCTION}

Quickly spreading from the United States in the global economy, the global financial crisis (GFC) has stood as further evidence for a highly globalised world. Particularly, the securitisation of the US sub-prime mortgages had a contagious effect on EU-28 credit markets. For the first time, EU-28 economic growth had a negative sign in 2009, affecting investments and business expectations in all Member States. Millions of employees have lost their jobs or experienced cuts in wages and other benefits. According to the International Labour Organization (ILO), global unemployment increased by 5 million in 2013, to a total of almost 202 million people. At the same time, the EU-28 unemployment rate rose in 5 years from $7.1 \%$ in 2008 to $10.9 \%$ in 2013 according to EUROSTAT (2014). Bakker - Zeng (2013) noted of that such high rates are paralleled with great differences among EU countries in post-crisis employment performance and argue that real economic growth, market duality, and corporate balance sheets have caused the divergence among the mentioned economies.

Androniceanu - Georgescu (2013) studied the insolvency problems that resulted from the GFC, particularly in Greece, Portugal, and Ireland. Lane - MilesiFerretti (2011) explained insolvency problems conditioning with large deficits in the pre-crisis period. Both the governments' and the private sectors' optimistic expectations in these countries were circumstanced by an economic activity boom in the pre-crisis period, which led them to enhance their spending. Meanwhile, facing an abrupt shrinkage of investments and rising unemployment, they were unable to withstand the damaging impact of the recent crisis alone, and turned to the IMF for financial assistance.

Despite the IMF's ongoing critiques, it has become a major player in crisis management. In order to ensure that it gets its money back and to reduce moral hazard, the Fund tied conditions to its programmes (Dreher 2009), which often entailed reduction in budget deficits, curbing of inflation, good track on debt service, and currency devaluation. Although the IMF Board of Governors considered achievement of a high level of employment and real income the overarching goal of the IMF already in 1946, IMF-style programmes were often coupled with notable social costs such as high unemployment, caps on wages, etc. (Vreeland 2002; Nooruddin - Vreeland 2010).

Most recently, the IMF (2013) has proclaimed job creation and inclusive growth as an imperative, and will provide policy advice and analyses to help Member States achieve the mentioned goals. We believe that recent changes in IMF policy and almost doubling of its budget could improve the effects on the economic situations of certain countries. Yet, Heise - Lierse (2011) note that public expenditure reduction is often driven by cutting welfare-state spending 
and by ubiquitous public layoffs. Notably, the authors underline that Romania cut social benefits by $15 \%$, while Greece reduced unemployment benefits by $22 \%$. In addition, Portugal, the UK, Hungary, and Latvia were not exempt from policies that curtailed social benefits. In the case of Romania, Androniceanu (2012) highlights that such a brusque shrinkage of social benefits may be caused by the lack of managerial capacity in the central government.

On the other hand, Caraway et al. (2012) found that IMF labour-related conditionality could be negotiated and minimised by national governments and that this is more likely to happen in democratic countries with strong labour institutions. Although few studies have addressed this issue, there is some empirical evidence for the adverse effects of IMF programmes on employment (Vreeland 2002; Nooruddin - Vreeland 2010). The dearth of sufficient evidence has been caused by the following four issues: the lack of data, selection bias, endogeneity, and adverse selection (Heckman 1979; Dreher 2006; Bas - Stone 2014). The first issue is solved by the IMF becoming more transparent and making all arrangements public. Still, the remaining three are still consistent and should be addressed when assessing IMF programmes.

Given that the IMF clients before the GFC were mostly developing countries with weak institutional fundamentals, it is of utmost interest to estimate the effects of IMF programmes on employment within the EU. Therefore, we put the following research question: Do IMF programmes lower employment once a country is under a programme, and if so, to what extent? Therefore, our study applies a with-and-without approach by creating counterfactuals by employing propensity score matching (PSM), which significantly reduces selection bias by controlling on observable variables. The remainder of the article is as follows: the theoretical and empirical evidence is presented in Section 2, Section 3 discusses the data and framework of estimation, while the results and discussions are provided in Section 4. Section 5 concludes.

\section{IMF PROGRAMMES AND EMPLOYMENT}

\subsection{Conditionality of loans}

One can distinguish between two types of loans: concessional and non-concessional. Concessional loans are provided to low-income countries only, and assume zero interest payments. In our research, we are interested in non-concessional loans, as between 1993 and 2013, no EU Member State benefited from concessional loans. Hence, the main lending toolkits for chosen countries are StandBy Arrangements (SBA) and Extended Fund Facility (EFF). The most common 
programme, as stated by Oberdabernig (2013), is a SBA that provides short-term assistance, usually for one to two years, and with higher conditionality compared to other types of IMF lending. The EFF, which lasts three years, is designed to tackle mid-term problems of balance of payments.

While the establishment of pre-conditionality was discussed by the Meltzer Commission (2004), the really important step was made in 2009 by creating two novel facilities based on ex-ante conditionality. The Flexible Credit Line (FCL) has lighter conditionality, but rigorous pre-selection. The Precautionary and Liquidity Line (PLL) is a mix of ex-ante and ex-post conditionality designed to meet urgent balance of payments needs. During the observation period among our countries, only Poland obtained a FCL in 2009. With such facilities, the IMF tries to reduce conditionality for developed countries, which over the years has been affecting governments' decisions to resort to the IMF.

Yet what exactly does conditionality mean and entail? Participation in an IMF programme is a joint decision of two negotiating sides: the IMF board and the government of the potential participant country. In general terms, conditionality is a set of requirements that the Fund attaches to the loan to assure stable economic growth and to guarantee the return of its money. Conway (2003) defines conditionality as the endogenous outcome of a bargaining process. Until the 1980s, conditionality was focused on macroeconomic policies, while by gradually increasing the programme-participation of low-income countries, it involved microeconomic indicators as well. However, there is a great difference of opinion in the literature about the effectiveness of conditionality due to the low compliance of governments. Lamdany (2009) concluded that the compliance rate was $60 \%$, which was comparatively higher in the core area of IMF competency. Brown's (2009) study of Latin America's conditional lending show that unemployment rates were higher in countries that turned to the Fund for assistance. Furthermore, Lane (2012) criticised the IMF for copying its standard practices for the EU Member States (Greece, Portugal, Ireland) without considering the domestic specifics.

\subsection{Theoretical effects of IMF conditionality on employment}

A common feature of IMF conditionality is a reduction of budget deficit. This can be achieved either by increasing budget revenue, or by cutting spending. Both methods are believed to have a negative impact on employment. Increasing budget incomes can be done through taxes and the privatisation of state-owned enterprises (SOE). Oberdabernig (2013) noted that because of uncertainty among business and the hampering effects on investments caused by taxation changes, 
governments often avoid such modifications. Instead, they are advised by IMF officials to cut the losses of SOEs, which often entails the privatisation of these enterprises coupled with public lay-offs. At the same time, reduction in public expenditures is less problematic. According to the IMF MONA database, of the 142 current IMF programmes, 120 have public expenditure reduction requirements. As Vreeland (2002) noted, cuts in public expenditures are often driven by new hiring in the public sector. Thus, it often leads to cuts and freezes in public wages, decrease in public employment, and curtailing social spending.

The influence of trade liberalisation on employment has an ambiguous effect. It could affect employment by lowering wages in state-protected sectors. At the same time, Handa - King (1997) claim that trade liberalisation contributes to labour-intensive sectors by increasing demand and wages. The other requirement that can influence employment is curbing inflation. The typical way to curb inflation is to increase interest rates, which has a hampering effect both on consumer and business demands. The former takes place due to costly credits and producers losing some of the benefits, while the latter has a negative impact on investments by making them expensive, which may cause a decrease in employment.

A recent study by IMF officials regarding the effects of IMF programmes on the labour force concludes that the IMF has recommended protection of workers through greater flexibility in wage-setting and the expansion of unemployment insurances (Blanchard et al. 2014). Thus, they found that the IMF advice was in place and that further responsibility for implementation needed to be shouldered by national governments through compliance. Yet, according to earlier discussions, the channels of the IMF influence on employment are indirect, rather than direct, through policy advice. Moreover, Dreher (2006) argues that the three components of IMF programmes, namely conditionality, lending, and policy advice, could have quite different impacts on the economy. Policy advice does not always entail that IMF programmes will have positive effects on employment, while further problems are due to either government incapacity to implement the recommendations or an unwillingness to follow them.

\subsection{Empirical evidence of IMF conditionality's impact on employment}

There are many studies that seek to study IMF programmes on incomes, which is necessarily related to employment to a certain extent; however, to the best of our knowledge, there is a lack of evidence regarding IMF programmes' direct effects on employment.

The first cross-country study of the IMF's impact on income distribution was conducted by Pastor (1987), in which he employed a "before-after" approach to 
compare the dependent variable before and after the implementation of an IMF programme, using non-programme countries as a control variable. Taking the evidence from 18 Latin American countries over a period from 1965 to 1981, the author found that IMF programmes contributed to the distribution of income away from workers. Garuda (2000) assessed the distributional effects of IMF programmes by employing a then new technique for controlling differences of initial economic circumstances of different countries based on Conway's (1994). He constructed propensity scores to tackle the problem of selection bias on observed variables. The findings claimed significant deterioration of income distribution in under-program countries when pre-program external imbalance was severe. However, Garuda's method did not cover the political variables that may influence a government's decision to resort to the IMF and further reduce the bias of omitted variable. Hence, our study attempts to fill this gap by introducing political factors such as availability of veto power, election year, etc. into the model.

The first study using parametric methods for controlling non-random selection was conducted by Vreeland (2002), in which the author used the dynamic version of Heckman's (1979) selection model to describe labour share in the income variable with 2095 observations over a period from 1961 to 1993 . He argues that the IMF participation contributes to raising inequality by lowering the labour share of income in the manufacturing sector. Moreover, labour is best off in countries never participating and worst off in countries currently participating in an IMF programme. Recently, Nooruddin - Vreeland (2010) too found adverse effects of IMF programmes on under-programme countries. In particular, countries under an IMF-supported programme were more likely to cut public wages and eliminate public jobs.

\section{METHODOLOGY AND DATA}

\subsection{Methodology}

In our case, we faced data limitations, as many new EU-member states were not independent economies prior to the regime change, and therefore the earliest available data are from 1993 only.

Faced with such limitations and motivated by Garuda (2000) and Hutchison's (2004) methodology, we have chosen to predict propensity scores and by matching them to measure average treatment effects on the treated (ATT). This is a very useful method in biostatistics, as it allows researchers to reveal the effects of medicine on a treatment group by comparing them with a control group (same 
health conditions without treatment). The same logic applies here, where IMF programmes assume the role of prescribed medicine for recipient countries. There are various methods of the evaluation of IMF programmes' effects dealing with selection problems, among them

- Heckman selection model (Heckit),

- Propensity Score Matching (PSM), and

- Instrumental - Variable (IV) approach.

However, the afore-mentioned methods claim certain requirements. Already Vreeland noted that large number of observations were required for the Heckit model and that he resolved the issue by employing the labour share of income from manufacturing as the dependent variable, which ensured 2095 observations, the longest series of data at that time. Since the scope of the current research is to reveal the impact of IMF programmes on employment in the EU Member States, we faced data limitations, as the IMF MONA database provides data on IMF arrangements since 1993. Thus, the maximum available sample for current research comprised 588 country-year observations, taking into consideration the availability of 21 years and $28 \mathrm{EU}$ member countries.

The IV approach can be conducted with fewer observations, as by Barro - Lee (2005), who used 613 observations and proximity to the EU and US as an instrumental variable. The idea of IV is to find variables that influence governments' decision to resort to the IMF, but without affecting the outcome variable. In our case, the political proximity to the EU and the US cannot be used as instrumental variables since the sample includes only EU states. As a kind of instrumental variable, Vreeland (2007) suggested the number of citizens that a certain country has at the IMF staff, as it may impact IMF participation, while it should not influence economic growth in that country. However, this information is not readily attainable, and thus we could not get access to this kind of data.

Although one major drawback of PSM is that it does not control for selection on unobservables, it does not require a large sample as soon as the propensity score is balanced within the treated and control groups. Moreover, Cepeda et al. (2003) used Monte Carlo simulations to compare logistic regression with propensity scores and concluded that the latter produced more accurate results given seven or less events per confounder. Hence, the most appropriate method in terms of data handiness and selection bias reduction is PSM combined with Differencein-Differences (DiD), where the latter completes PSM by combating the issue of unobservables. The choice of the ATT parameter is motivated by its ability to assess the success of IMF programmes by evaluating treated countries that the programmes had been initially designed for (Heinrich et al. 2010). Moreover in the case of ATT, the two following assumptions on unconfoundedness and com- 
mon support could be weakened by only satisfying the mean independence of the treatment and control groups. Having those assumptions, the general equation of PSM for ATT can be determined as:

$$
\mathrm{T} \underset{A T T}{P S M}=E_{P(X) \mid D=1}\{E[Y(1) \mid D=1, P(X)]-E[Y(0) \mid D=0], P(X)\} .
$$

The equation could be interpreted as the mean difference between outcomes over the common support weighted by the propensity score distribution of participants. Caliendo - Kopeinig (2008) already highlighted that PSM is not a "magic bullet" to solve all problems related to the evaluation. Therefore, it should be employed whenever selection on observables or conditional dependence is best approached based on a thorough understanding of the issue and information richness of data.

However, by conditioning observable covariates, equation (1) means that the outcome is not correlated (mean-independent) with IMF programme participation. In order to loosen this strong assumption, the current research employs DiD and regression-adjusted matching estimators. The DiD uses a semi-parametric technique to build differences by comparing the employment rate (outcome variable) of the treated countries before and after participation with the employment rate of untreated countries (Heckman et al. 1998). Smith - Todd (2005) noted that the DiD estimator allows a non-linear relationship between the treatment and outcome variables by balancing the observations. Since our chosen parameter is ATT, the combination of PSM with the DiD approach can be described with the following equation:

$$
\begin{aligned}
& \mathrm{T} \underset{A T T}{P S M-D I D}=E\left[Y t(0)-Y_{t_{-} 1}(0) \mid P(X), D=1\right]=E\left[Y_{t}(0)-\right. \\
& \left.-Y_{t_{-} 1}(0) \mid P(X), D=0\right]
\end{aligned}
$$

where $t$ is the after- and $t_{1}$ is the prior-programme participation period. This too demands satisfaction of overlap assumption. Since the data employed in the research are panel data, they allow the estimation of PSM in both after- and priorparticipation periods and then measure the difference between them easily by distinguishing participants from non-participants. Moreover, according to Smith - Todd (2005), such a DiD estimator with panel data is less sensitive than matching estimators based on cross-section data.

Furthermore, by consulting the literature on the appropriate model to calculate propensity scores, the preference was given to the probit model, which combats the drawback of linear probability models, i.e. it calculates highly-skewed variables and makes predictions out of a $[0,1]$ interval of probabilities. 
The calculation of propensity scores is followed by the employment of matching methods to deal with sample selection bias. There are different algorithms designed to execute matching based on the ATT parameter, of which we have employed the following four: nearest neighbour (ATTN), radius (ATTR), stratification (ATTS), and kernel (ATTK). Those four were included in the analyses, as there is no universally-recognised matching algorithm to treat all cases appropriately. In addition, the estimation of these four matching methods enables checking for the robustness of the results. In addition, a regression-adjusted (RA) matching estimator was employed to correct biases from omitted variable by incorporating the above-mentioned algorithms with regression-adjusted covariates (Heckman et al. 1998). More precisely, the RA provides an opportunity to solve the drawback of Local Linear Matching estimators (e.g. ATTN, ATTR, ATTS, ATTK), which fail to address the linkage between treatment variable and the outcome variable. Therefore, the regression-adjusted estimators utilised the existing difference of covariates to decrease the potential bias caused by the likelihood of not correct matching.

It must be noted that all these methods have to be implemented only when the common support and the overlap assumption are satisfied. This can be checked either by the visual analysis of propensity score distribution in the control and treatment groups or by trimming the sample and with minima and maxima comparison. In the case of ATT, the sufficient requirement is to ensure that there are matches in the control group.

\subsection{Data and choice of covariates}

This study used cross-country data for 28 EU Member States over the period between 1993 and 2013. The sample included only concessionary loans, where the basic facilities were SBAs and FCLs with a two-year duration. ${ }^{1}$ The changes in employment and youth employment rates (EMPR and YEMPR) were chosen as our outcome variables, while changes in unemployment (UNEMPR) were used for sensitivity checks of matching methods. It was assumed that the ATT for outcome variable EMPR and UNEMPR should be in different directions in order to show that the results are not driven by a particular specification.

Table 1 illustrates descriptive statistics of both outcome variables and covariates sorted by their participation in an IMF programme, coded 0 and 1 for non-

Due to space limitation, information about countries and number of years spent under IMF programmes, figures and conducted test results are available only upon request from the authors. 
participation and participation, respectively. For avoiding the problem of endogeneity and simultaneity, Sturm et al. (2005) advise to employ IMF participation determinants with a one-year lag. Therefore, we first calculated propensity scores for the theoretical assumptions about the relationship between determinants and IMF participation, which is shown in the first column of Table 2. Then, propensity scores were calculated based on one-year lagged covariates, which are presented in column 2 of Table 2.

There are specific methods for identifying the worthiness of the inclusion of covariates: statistical significance, hit or miss, and leave-one-out cross-validation. Since our covariates are balanced and define IMF programme participation in the right direction, we left statistically non-significant variables in the probit model for the further reduction of bias related with omitted variables. In addition, Rubin - Thomas (1996) argue that covariates should be eliminated only if they are not proper or are not related to the outcome.

Based on previous findings on the importance of political determinants in the choice to participate in an IMF programme, our study includes both economic and political variables in order to further reduce the bias of omitted variables. Particularly, Knight - Santaella (1997) found that participation in an IMF programme was not random and demonstrated that low GDP per capita, weak economic growth, and reduction in investments and international reserves were major determinants of the governments' decision. Additionally, the shrinkage of the current account balance (CAB) as a percentage of GDP has been shown to be an important determinant (Nooruddin - Woo 2015), and countries experiencing high inflation and carrying high government debt are likely to participate in IMF programmes (Moser - Sturm 2011).

Apart from economic covariates, there is a broad consensus that political factors could drive government's decision to resort to the IMF. Vreeland (2004) found that the availability of veto players (CHECKS) could motivate governments to apply to the IMF, reducing the likelihood of veto. Thus, the logarithm of CHECKS was employed in our regression. Furthermore, Przeworski - Vreeland (2000) concluded that countries after elections were more likely to enter into an arrangement; hence, the lagged legislative elections (LEGELEC1) variable was incorporated into the model. Another important variable is government stability, which is negatively correlated with IMF participation according to Sturm et al. (2005). In addition, Vreeland (2006) found that past participation in an IMF programme could positively impact the government's decision. Therefore, cumulative years under IMF programme (SUMUN) and participation in the past (PASTAG) were used as covariates in the analysis. 
Table 1. Descriptive statistics

\begin{tabular}{|c|c|c|c|c|c|c|c|c|c|c|}
\hline & 0 & 1 & 0 & 1 & 0 & 1 & 0 & 1 & 0 & 1 \\
\hline Variable & Obs & Obs & Mean & Mean & $\begin{array}{l}\text { Std. } \\
\text { Dev. }\end{array}$ & $\begin{array}{l}\text { Std. } \\
\text { Dev. }\end{array}$ & Min & Min & Max & Max \\
\hline yemprate & 460 & 100 & -.871 & -3.29 & 6.25 & 6.69 & -22.4 & -26.14 & 43.98 & 13.47 \\
\hline emprate & 482 & 90 & .721 & -1.15 & 2.30 & 3.16 & -10.2 & -14.3 & 10.95 & 4.41 \\
\hline inv1 & 454 & 92 & 22.64 & 21.60 & 4.27 & 6.02 & 11.4 & .103 & 39.55 & 39.95 \\
\hline cab1 & 452 & 100 & -2.18 & -4.74 & 15.25 & 5.21 & -154.1 & -24.10 & 44.62 & 8.63 \\
\hline infl & 456 & 100 & 7.99 & 27.04 & 72.43 & 112.04 & -1.70 & -1.57 & 1517 & 1061 \\
\hline growth & 448 & 92 & 2.50 & 2.74 & 3.36 & 4.86 & -14.84 & -17.70 & 10.98 & 11.74 \\
\hline gdppc1 & 470 & 96 & 27,247 & 13,910 & 12,495 & 8,847 & 5462 & 5790 & 91,642 & 45,756 \\
\hline gdebt & 438 & 98 & 54.96 & 45.31 & 28.25 & 38.00 & -3.64 & 4.79 & 137.5 & 170.32 \\
\hline reserve & 448 & 88 & 2.01 & 4.01 & 1.81 & 2.61 & .010 & 0.66 & 7.95 & 8.90 \\
\hline pastag & 482 & 106 & .217 & .258 & .413 & .412 & 0 & 0 & 1 & 1 \\
\hline sumun & 482 & 106 & 1.37 & 5.67 & 3.18 & 3.74 & 0 & 1 & 14 & 15 \\
\hline logchecks & 458 & 99 & 1.40 & 1.28 & .307 & .368 & 0 & .693 & 2.30 & 2.08 \\
\hline stabs & 457 & 98 & .148 & .162 & .285 & .293 & 0 & 0 & 1 & 1 \\
\hline legelec1 & 458 & 102 & .268 & .245 & .443 & .432 & 0 & 0 & 1 & 1 \\
\hline
\end{tabular}

Source: Authors' calculation.

Table 1 shows that IMF participation counted around 100 country-year observations, which is about $18 \%$ of the full sample. Furthermore, it can be noted that during the observed period, IMF participants were, on average, in worse conditions than non-participants. The latter corroborates the assumption that countries participating in IMF programmes had serious economic problems and that the above-discussed determinants may influence a government's decision to participate in IMF programmes. More precisely, it assumes that states with low GDP per capita, higher inflation, low investment rates, and lower economic growth are more likely to turn to the IMF for financial assistance.

It must be noted that Moser - Sturm's (2011) review of 17 studies on determinants of IMF programme participation did not find labour market variables as determining factors for governments to turn to the IMF. This may further reduce probability of "Ashenfelter's dip" in our study, i.e. a decrease in employment is less likely to affect governments' decision to participate in IMF programmes. To test the availability of dip, we composed graphs with these two variables for the 14 countries that have participated in an IMF programme and two not-participant countries (Spain and Slovenia) in the observed period. 


\section{EFFECTS OF IMF PROGRAMMES ON EMPLOYMENT: EMPIRICAL EVIDENCE}

\subsection{Propensity score estimation and matching}

Propensity scores were calculated employing probit regression using the "teffectpsmatch" package in the Stata 13 software. First, we calculated the score based on the full sample with 477 observations. Then, the trimmed sample was employed, after eliminating countries that never participated in IMF programmes during the observed period. Table 2 shows the output of our regression, where pseudo $\mathrm{R}^{2}$ for regression comprised $0.51,0.52$, and 0.31 for Models 1,2 , and 3 . The third model represents regression based on the trimmed sample. The models precisely predict $71 \%, 74 \%$, and $75 \%$ of IMF participation, respectively, based on calculated propensity scores. We use blockid in the specification to split the sample into blocks based on scores, which are 6 and 5, respectively, for the full and the trimmed samples. The balancing property was automatically run and has been satisfied, which means that in each of these blocks, not only the propensity scores were similar, but also the covariates on which we match.

Before discussing the correlation of the obtained coefficients with our treatment variable, it must be noted that the common support option has been selected. The common support condition is valid, as countries with the same features cannot be observed in both the treated and the control group. The regions of common support are $(0.012,0.976)$ and $(0.025,0.961)$ for the full and the trimmed samples, respectively. Thus, the requirement on common support has been ensured, which, according to Heckman et al. (1997), is a major source of biased propensity score assessment. In order to check the overlap assumption, the distributions of propensity scores for full and trimmed samples have been plotted. It is revealed that there were no substantial differences between the distributions and that they were spread asymmetrically within the control and the treated groups. The slight inclination towards the rump in the trimmed sample illustrates that countries in the treatment group were more likely to resort to the IMF. To complete the checks, the kernel density of propensity scores has been estimated based on the Epanechnikov function with 0.023 bandwidth, where the graph revealed that the measured propensities, namely that an under-programme country would be under-programme and a non-programme country would not participate in IMF programmes, were in the area of coincidence.

The correlation of covariates with the IMF participation dummy was consistent with theoretical assumptions and previous empirical findings. It was estimated that in the observed period, countries experiencing low contemporaneous economic growth and international reserves, decrease in investments and in cab, 
higher inflation, and government debt were more likely to resort to the IMF. Yet, among those six covariates, cab1 was not statistically significant in Model 1, while it became significant at the 5\% level in Model 2 employing its logarithm value.

Table 2. Propensity score calculation with a probit model

\begin{tabular}{|c|c|c|c|c|}
\hline \multicolumn{2}{|c|}{ Model 1} & \multicolumn{2}{|c|}{ Model 2} & \multirow{2}{*}{\begin{tabular}{|r|} 
Model 3 \\
Coefficient
\end{tabular}} \\
\hline Covariates & Coefficient & Covariates & Coefficient & \\
\hline gdppc1 & $\begin{array}{c}-.001 \\
(.000 * * *) \\
\end{array}$ & $\operatorname{loggdppc1}$ & $\begin{array}{c}-.042 \\
(.018) * * *\end{array}$ & $\begin{array}{c}-.023 \\
(.007)^{* * *}\end{array}$ \\
\hline growth & $\begin{array}{c}-.038 \\
(.029 * *)\end{array}$ & growth1 & $\begin{array}{c}-.034 \\
(-.009) * * *\end{array}$ & $\begin{array}{c}-.029 \\
(.009)^{* *}\end{array}$ \\
\hline inv1 & $\begin{array}{c}-.077 \\
(.030 * *)\end{array}$ & $\operatorname{loginv} 1$ & $\begin{array}{c}-.036 \\
(.012) * * *\end{array}$ & $\begin{array}{c}-.045 \\
(.002)^{* *}\end{array}$ \\
\hline infl & $\begin{array}{c}.071 \\
\left(.026^{* *}\right)\end{array}$ & $\operatorname{loginfl} 1$ & $\begin{array}{c}.052 \\
(.037) * * *\end{array}$ & $\begin{array}{c}.044 \\
(.040)\end{array}$ \\
\hline gdebt & $\begin{array}{c}.017 \\
\left(.006^{* * *}\right)\end{array}$ & gdebt1 & $\begin{array}{c}.008 \\
(.001)^{* *}\end{array}$ & $\begin{array}{c}.011 \\
(.003)^{* *}\end{array}$ \\
\hline reserve & $\begin{array}{c}-.031 \\
\left(.013^{* *}\right)\end{array}$ & reserve1 & $\begin{array}{c}-.021 \\
(.001) * *\end{array}$ & $\begin{array}{c}-.027 \\
(.001)^{* *}\end{array}$ \\
\hline cab1 & $\begin{array}{c}-.018 \\
(-.006)\end{array}$ & $\log c a b 1$ & $\begin{array}{c}-.016 \\
(.005) * *\end{array}$ & $\begin{array}{c}-.008 \\
(.004)^{*}\end{array}$ \\
\hline pastag & $\begin{array}{c}1.28 \\
\left(.386^{* * *}\right)\end{array}$ & pastag & $\begin{array}{c}1.72 \\
(.089) * * *\end{array}$ & $\mathrm{~N} / \mathrm{A}$ \\
\hline sumun & $\begin{array}{c}.174 \\
(.040 * * *)\end{array}$ & sumun & $\begin{array}{c}.122 \\
(.010) * *\end{array}$ & $\begin{array}{c}.132 \\
(.012)^{* *}\end{array}$ \\
\hline logchecks & $\begin{array}{c}.822 \\
(.041 *)\end{array}$ & logchecks1 & $\begin{array}{c}.631 \\
(.398) *\end{array}$ & $\begin{array}{c}.724 \\
(.376)^{*}\end{array}$ \\
\hline stabs & $\begin{array}{c}-.631 \\
(-.495) \\
\end{array}$ & $\operatorname{logstabs} 1$ & $\begin{array}{c}-.326 \\
(.129) * * \\
\end{array}$ & $\begin{array}{c}-.277 \\
(.142)^{* *} \\
\end{array}$ \\
\hline legelec1 & $\begin{array}{c}.145 \\
(-.321) \\
\end{array}$ & legelec 1 & $\begin{array}{c}.007 \\
(-.098) \\
\end{array}$ & $\begin{array}{c}.051 \\
(.113) \\
\end{array}$ \\
\hline intercept & $\begin{array}{c}-2.10 \\
(-1.52 * * *)\end{array}$ & intercept & $\begin{array}{c}.932 \\
(-.467)^{* * *}\end{array}$ & $\begin{array}{c}.707 \\
(.442)^{* * *}\end{array}$ \\
\hline Observations & 477 & & 468 & 154 \\
\hline Chi squared & 187.5 & & 184.0 & 60.2 \\
\hline Pseudo R squared & .513 & & .521 & .312 \\
\hline Correct prediction & .71 & & .74 & .75 \\
\hline
\end{tabular}

Notes: Standard errors in parentheses. * Significant at the $10 \%$ level; ** significant at the $5 \%$ level; *** significant at the $1 \%$ level ; N/A: pastag in the trimmed sample was dropped due to collinearity.

Source: Authors' calculation. 
As it has been supposed, countries with lower income resorted to the IMF more often, which was indicated by the first year lagged value of GDP per capita in the model.

The estimated coefficients of political covariates underpin the theoretical considerations. More precisely, there is evidence that past experience of collaboration with the IMF makes it more probable for countries to become involved in IMF programmes. Furthermore, the availability of veto players (logchecks) or an increase in their number has been positively correlated, being significant at the $10 \%$ level. Another two political covariates, government stability (stabs) and prior legislative elections (legelec1), though non-significant statistically, prove that the theoretical assumptions have been correct, i.e. government instability and prior elections could lead to IMF participation. It should be noted that in the second specification and with the trimmed sample, the covariate of government stability was introduced with a one-year lag and by its logarithmic value (logstabs1), which was statistically significant at the $5 \%$ level, preserving negative and even strengthened correlation with IMF participation.

In the trimmed sample, the coefficients have been intensified by revealing a stronger correlation between the dependent and independent variables. Furthermore, we have estimated the probit model by introducing higher-order terms in the specification. Dehejia - Wahba (2002) found this method useful for obtaining a balancing property within each stratum. In our case, the balancing property has been satisfied by the initial specification. However, by employing the squared and logarithm values of covariates, some improvements were achieved, bringing evidence that the results are persistent and further average treatment effect could be measured.

The optimal number of blocks for both full and trimmed samples, where the balance of propensity scores is obtained, has been chosen. This number of blocks ensures that the mean propensity score is not different for the treated and the controls in each block, and define the inferior bounds of blocks. Aakvik (2001) found it sufficient to justify the choice of the blocks via securing the balance of propensity scores within each block.

\subsection{Matching results and effects of IMF programmes on employment}

We evaluated the effects of IMF programmes in the programme initiation year, and two years after initiation, given the wide consensus in the literature regarding the lagged effects of IMF programmes. In particular, of the three components of IMF programmes, only lending may have an immediate effect on economies, while policy advice and conditionality have a lagged impact due to the interval 
between domestic policy design and implementation. Table 3 presents matching results based on regression-adjusted residuals (Rubin residuals), while Tables 4 and 5 illustrate results obtained by matching on residuals of Model 2. Given the limited number of observations, the current research conducted matching involving Rubin residuals since it incorporates the full sample, while Heckman residuals are measured based on the non-participation sample. In order to carry out the Rubin regression-adjusted matching estimator, we first measured a specification that controls for the factors different from IMF participation, which still may impact the assessment of employment rate. Then, the residuals, i.e. unexplained employment growth, are compared for recipient and non-recipient observations employing the four afore-mentioned matching algorithms (Table 3).

To reduce the variance, all matching methods include errors bootstrapping, which was ordered to implement 150 iterations per method. The scope of these iterations is to approximate the sample distribution to its mean. Furthermore, by consulting the literature, it has identified a 0.05 interval as being appropriate for defining the maximum distance of propensity scores in the radius algorithm (Hutchison 2004; Heinrich et al. 2010; Roman - Popescu 2014). Furthermore, we have implemented matching on the full and the trimmed samples to check the robustness. In both cases, no major violations of the assumption we observed, which allowed drawing important conclusions.

All four algorithms revealed the IMF programmes' negative impact on employment $(-0.6,-1 \%)$, where $t$-statistics show that all coefficients are signifi-

Table 3. IMF programmes effects by Rubin regression-adjusted residuals matching with DiD estimator

\begin{tabular}{l|c|c|c|c}
\hline \hline & ATTN & ATTR (0.05) & ATTK & ATTS \\
\hline Contemporaneous effects on employment rate (Model 6) & \multicolumn{1}{l}{} \\
\hline \hline Estimated IMF impact & -.642 & -.715 & -.428 & -.606 \\
\hline T-stat & 3.224 & 2.125 & 2.837 & 2.328 \\
\hline Number of observations & 91 & 279 & 286 & 286 \\
\hline Employment rate DiD (Model 6) & -.507 & -.641 & -.397 & -.579 \\
\hline \hline Estimated IMF impact & 3.276 & 2.745 & 2.214 & 3.083 \\
\hline T-stat & 89 & 276 & 282 & 282 \\
\hline Number of observations & -.128 & -.342 & .157 & -0.089 \\
\hline \hline Two-year effects on employment rate (Model 6) & 2.151 & 2.462 & 1.559 & 2.083 \\
\hline Tstimated IMF impact & 89 & 277 & 284 & 284 \\
\hline Number of observations &
\end{tabular}

Abbreviations: Nearest neighbour (ATTN), radius (ATTR), kernel (ATTK), stratification (ATTS) effects. Source: Author's calculation. 
Table 4. Average treatment effect in program year

\begin{tabular}{l|c|c|c|c}
\hline & ATTN & ATTR (0.05) & ATTK & ATTS \\
\hline Employment (full sample) & -1.092 & -.989 & -.603 & -.799 \\
\hline Estimated IMF impact & -2.028 & -2.296 & -1.987 & -2.182 \\
\hline T-stat & -.285 & -.293 & -.584 & -.346 \\
\hline Employment (trimmed sample) & -3.040 & -1.129 & -.806 & -2.522 \\
\hline Estimated IMF impact & .919 & -1.530 & -.240 & -1.014 \\
\hline T-stat & .265 & -1.326 & -2.261 & -2.006 \\
\hline Youth employment (full sample) & \multicolumn{1}{l}{} \\
\hline Estimated IMF impact & .041 & -.337 & -.178 & -.099 \\
\hline T-stat & 2.223 & -2.897 & -2.038 & -.510 \\
\hline Youth employment (trimmed sample) & \multicolumn{1}{l}{} \\
\hline Estimated IMF impact & .976 & .412 & -.771 & .274 \\
\hline T-stat & 1.702 & 2.168 & -1.081 & 1.338 \\
\hline Unemployment (full sample) & .752 & .737 & -.096 & .157 \\
\hline Estimated IMF impact & 4.537 & 3.424 & -.154 & 3.111 \\
\hline T-stat & 93 & 284 & 291 & 291 \\
\hline Unemployment (trimmed sample) & 123 & 138 & 138 \\
\hline Estimated IMF impact & 83 &
\end{tabular}

Abbreviations: See Table 3.

Source: Authors' calculation.

cant on conventional levels, except the kernel method that fell between $-2,2$. These adverse effects palpably decreased over the period, but still remained negative $(-0.64 \%,-0.36 \%)$ after two years of programme initiation, where kernel matching found positive, but non-significant effects on employment. Moreover, evidence from the trimmed sample suggests that employment declined more in under-programme countries than in non-participants, attributing negative impacts to the IMF programmes both in the programme year and after two years.

Except for ATTN, the remaining three methods found that IMF affects youth employment in the programme initiation year $(-0.24 \%,-1.5 \%)$, where ATTR and ATTS coefficients were significant. In contrast, ATTN, although insignificant, showed that there might be a positive $(0.91 \%)$ influence. Implementation of the same operations with the trimmed sample reduced the negative impact by up to $(-0.09 \%,-0.34 \%)$, with significant coefficients from radius and kernel matching. At the same time, the ATTN coefficient became significant, while virtually identical to those with negative findings. The situation notably improves with the two-year impact of IMF programmes on youth employment. The ATTN and 
Table 5. Average treatment effect after 2 years of program initiation

\begin{tabular}{|c|c|c|c|c|}
\hline & ATTN & $\operatorname{ATTR}(0.05)$ & ATTK & ATTS \\
\hline \multicolumn{5}{|c|}{ Employment (full sample) } \\
\hline Estimated IMF impact & -.133 & -.642 & .164 & -.097 \\
\hline T-stat & -2.326 & -1.298 & 1.115 & -2.855 \\
\hline \multicolumn{5}{|c|}{ Employment (trimmed sample) } \\
\hline Estimated IMF impact & -.278 & -.093 & -.413 & -.108 \\
\hline T-stat & -4.354 & -1.783 & 1.567 & 3.222 \\
\hline \multicolumn{5}{|c|}{ Youth employment (full sample) } \\
\hline Estimated IMF impact & 1.219 & -.879 & .256 & -.688 \\
\hline T-stat & 1.578 & -2.319 & .404 & -1.077 \\
\hline \multicolumn{5}{|c|}{ Youth employment (trimmed sample) } \\
\hline Estimated IMF impact & .745 & -.907 & .046 & -.573 \\
\hline T-stat & -3.001 & 1.989 & .007 & -1.374 \\
\hline \multicolumn{5}{|c|}{ Unemployment (full sample) } \\
\hline Estimated IMF impact & .563 & .357 & -.551 & .226 \\
\hline T-stat & 2.224 & 2.887 & -.654 & 2.741 \\
\hline \multicolumn{5}{|c|}{ Unemployment (trimmed sample) } \\
\hline Estimated IMF impact & .896 & -.471 & -.143 & .186 \\
\hline T-stat & 3.635 & -1.338 & -.154 & 4.252 \\
\hline Full observations & 91 & 238 & 258 & 258 \\
\hline Trimmed observations & 79 & 117 & 129 & 129 \\
\hline
\end{tabular}

Source: Author's calculation.

ATTK found that after participation in IMF programmes, youth employment increased $(0.04 \%, 1.2 \%)$ in countries initiating IMF participation. However, ATTR and ATTS still revealed a negative impact on youth employment in the states with IMF programmes. The differences in the latest two are significant at conventional levels, while a positive impact is consistent with ATTN in the trimmed sample.

Furthermore, in order to test the sensitivity of obtained results, the average treatment effects of IMF participation have been measured using unemployment as the outcome variable. This test may confirm that the results are persistent, since they were identical to those with employment. Although statistically nonsignificant at conventional levels in some cases, it is interesting that most of the results show palpable negative effects due to IMF programme participation, with the largest negative contemporaneous effects being a decrease of $-1.01 \%$ and $-0.28 \%$, respectively, after two years of initiation.

The matching based on Rubin regression-adjusted residuals reveals that IMF programme participation has a negative impact on employment both in the programme year and after two years of programme initiation, corroborating the results presented in Tables 4 and 5. Particularly, statistically significant negative 
coefficients have been gauged by four matching algorithms in average reducing employment by $-0.59 \%$ in the programme initiation year. Although the negative effects of IMF programme participation were notably reduced after two years of programme participation, they still remained, resulting a $-0.1 \%$ reduction in employment rate (Table 3).

The estimation of employment rate differences between programme and nonprogramme observations too indicated the negative contemporaneous effects of programme participation on employment. Thus, controlling for unobservable variables by the DiD estimator in average IMF programme participation reduced the employment rate by $-0.53 \%$ during the $1993-2013$ period. In sum, the results demonstrate that employment rate is notably affected by IMF programmes, which are supported statistically significant coefficients once one controls for selection both on the observable and unobservable variables.

\section{DISCUSSION AND CONCLUDING REMARKS}

Our study sought to reveal IMF programme effects on employment within the EU. Of the 28 EU Member States, only 14 have participated in an IMF programme between 1993 and 2013. Moreover, of those participating countries, 10 are former socialist countries and of this group, only Slovenia has not turned to the IMF for assistance in the observed period. In the euro zone, Greece, Ireland, Portugal, and Cyprus have accepted IMF conditions, which were conditioned by the recent financial crisis that led to insolvency problems. This was the first time since the 1980s that the IMF gave loans to developed countries. Thus, one may consider that it is a step forward towards its roots as a global institution, which was created to solve problems of balance of payment and to ensure long-term growth not only for its low-income members.

The few studies devoted to evaluating the effects of IMF participation on employment have found adverse effects on employment. Particularly, Pastor (1987) and Vreeland (2002) examined the income distribution effects under IMF programmes and concluded that by further deteriorating income distribution, labour was worse off in recipient countries in terms of income. However, the first study did not reckon with the problem of non-random selection, while the dependent variable in the second one was the labour share of income from manufacturing, which was the biggest available data on that moment, even though the assumption that manufacturing is the main sector in the economy of under-programme countries was a serious abstraction. Later, Nooruddin - Vreeland (2010) found that countries participating in IMF programmes tended to lower public salaries and wages, while the temporary members of the United Nations Security Council 
were in favourable conditions and even increased wages and salaries. Moreover, the assessment of the employment rate of EU members participating in the IMF programmes offered another opportunity to reveal whether the ability of democratic countries to negotiate labour conditionality (Caraway et al. 2012) mitigates the adverse effects of IMF programmes on employment. Our study confirms previous empirical findings by demonstrating the negative impact of IMF participation on employment in the short-term, having controlled for selection on observables using the propensity score matching method. In particular, we found that IMF participation lowered total employment by $-0.87 \%$ in the programme year and by $-0.11 \%$ after two years of programme initiation. These averages are calculated based on statistically-significant coefficients. However, based on Rubin regression-adjusted residuals, the average negative impact decreased by $-0.59 \%$ for contemporaneous effects and by $-0.1 \%$ for the two-year effect, but the robustness of the coefficients were significantly improved. The results remain persistent once we control for selection on unobservables employing the DiD estimator, where the IMF programmes decrease employment by $-0.53 \%$ on average, with all coefficients statistically significant at conventional levels. Even though the IMF advises governments to protect employment, its conditionality requires contractionary policies such as curbing inflation and budget deficit reduction, which is often achieved by wage freezes in the public sector, caps on salaries, and even the elimination of public jobs.

One of the four algorithms employed to estimate the effect in the trimmed sample revealed a significant positive effect, $0.74 \%$ and $0.41 \%$, respectively, both in the programme year and after two years. Moreover, the nearest neighbour method on the full sample has also identified a positive, although non-significant impact in both cases. At the same time, the three others found a negative impact on youth employment in the programme year on average, lowering youth employment for the full and trimmed samples by $-0.63 \%$ and $-0.26 \%$, respectively. While statistically insignificant, it is noteworthy that the IMF may have a positive impact on youth employment after governments' compliance on conditionality. Thus, we conclude that due to contractionary conditions, the IMF programmes' immediate impact on youth employment is negative, while it is likely to contribute to the improvement in youth employment after two years of programme initiation.

Propensity score matching was employed in this study, which partially solves the bias of selection, controlling it just on observables. It lacks to control on unobservables and to treat adverse selection caused by bad type government. Hence, PSM has been used in combination with the $\mathrm{DiD}$ estimator, which partially address the problem of unobservables. Apart from economic covariates, the current study has introduced political variables in probit regression, which replenishes Garuda's (2000) study, where the author calculated the scores based 
solely on economic factors. Furthermore, as has been advised, we have employed not just linear correlations, but higher-order terms (logarithmic and squared values of covariates) on the model to better define propensity scores.

In order to ensure the robustness of the results, we utilised four different types of matching algorithms: nearest neighbour, radius, kernel, and stratification. To shed light on the rigorousness of the results and to show the likelihood of the results to be driven by a particular specification is low, the matching has been applied to both the full and the trimmed sample. The sample was trimmed by eliminating countries that have never participated in the programme during the observed period, taking into consideration the Heckman et al.'s (1997) assumption that the treatment effect should be measured for whom it has been designed. In addition, the average treatment effect on changes in unemployment was estimated to check the sensitivity of results and found the results to be persistent.

Since our goal has been to reveal the IMF effects on employment in the EU, we have employed a restricted sample, which should further be enhanced and encompasses all countries for the given period, where by using other models, regional dummy variables could be included to identify the effects in different regions. Another option could be separation of states with independent and dependent monetary policies since there is evidence that employment in countries with restricted independence of monetary policy is more affected. It will be interesting to observe IMF programme effects on other labour market outcomes, to evaluate whether public or private employment, female and male workers, or qualified and blue-collar personnel are more affected. It should be mentioned that the applied method may still contain bias, which should be addressed in further studies.

\section{REFERENCES}

Cepeda, M. S. - Boston, R. - Farrar, J. T. - Strom, B. L. (2003): Comparison of Logistic Regression versus Propensity Score When the Number of Events is Low and There Are Multiple Confounders. American Journal of Epidemiology, 158(3): 280-287.

Conway, P. (1994): IMF Lending Programs: Participation and Impact. Journal of Development Economics, 45(2): 365-391.

Conway, P. (2003): Endogenous IMF Conditionality: Theoretical and Empirical Implications. University of North Carolina.

Dehejia, R. H. - Wahba, S. (2002): Propensity Score-Matching Methods for Nonexperimental Causal Studies. Review of Economics and Statistics, 84(1): 151-161.

Dreher, A. (2006): IMF and Economic Growth: The Effects of Programs, Loans, and Compliance with Conditionality. World Development, 34(5): 769-788.

Dreher, A. (2009): IMF Conditionality: Theory and Evidence. Public Choice, 141(1-2): 233-267. 
Garuda, G. (2000): The Distributional Effects of IMF Programs: A Cross-Country Analysis. World Development, 28(6): 1031-1051.

Handa, S. - King, D. (1997): Structural Adjustment Policies, Income Distribution and Poverty: A Review of the Jamaican Experience. World Development, 25(6): 915-930.

Heckman, J. J. (1979): Sample Selection Bias as a Specification Error. Econometrica: Journal of the Econometric Society, 153-161.

Heckman, J. - Ichimura, H. - Smith, J. - Todd, P. (1998): Characterizing Selection Bias Using Experimental Data. Working Paper, No. 6699. National Bureau of Economic Research.

Heckman, J. J. - Ichimura, H. - Todd, P. E. (1997): Matching as an Econometric Evaluation Estimator: Evidence from Evaluating a Job Training Programme. The Review of Economic Studies, 64(4): 605-654.

Heinrich, C. - Maffioli, A. - Vazquez, G. (2010): A Primer for Applying Propensity-Score Matching. Technical Notes, No. IDB-TN-161, Inter-American Development Bank.

Heise, A. - Lierse, A. (2011): Budget Consolidation and the European Social Model. The Effects of European Austerity Programmes on Social Security Systems. Friedrich Ebert Foundation.

Hutchison, M. M. (2004): Selection Bias and the Output Costs of IMF Programs. EPRU Working Paper Series, No. 2004-15. University of Copenhagen.

IMF (2013): Factsheet: The IMF and Europe. Washington, D.C.

Knight, M. - Santaella, J. A. (1997): Economic Determinants of IMF Financial Arrangements. Journal of Development Economics, 54(2): 405-436.

Lamdany, R. (2009): Assessing the Effectiveness of IMF Structural Conditionality. The Journal of Social Science, 68(1): 133-148.

Lane, P. R. (2012): The European Sovereign Debt Crisis. The Journal of Economic Perspectives, 26(3): 49-67.

Lane, P. R. - Milesi-Ferretti, G. M. (2011): The Cross-Country Incidence of the Global Crisis. IMF Economic Review, 59(1): 77-110.

Meltzer, A. H. (2004): The Report of the International Financial Institution Advisory Commission: Comments on the Critics. In: Vines, D. (ed.): The IMF and its Critics: Reform of Global Financial Architecture. Global Economic Institutions series, No. 5, pp. 106-123.

Moser, C. - Sturm, J. E. (2011): Explaining IMF Lending Decisions after the Cold War. The Review of International Organizations, 6(3-4): 307-340.

Nooruddin, I. - Vreeland, J. R. (2010): The Effect of IMF Programs on Public Wages and Salaries. Global Governance, Poverty and Inequality, No. 90.

Nooruddin, I. - Woo, B. (2015): Heeding the Sirens: The Politics of IMF Program Participation. Political Science Research and Methods, 3(01): 73-93.

Oberdabernig, D. A. (2013): Revisiting the Effects of IMF Programs on Poverty and Inequality. World Development, 46: 113-142.

Pastor, M. (1987): The Effects of IMF Programs in the Third World: Debate and Evidence from Latin America. World Development, 15(2): 249-262.

Przeworski, A. - Vreeland, J. R. (2000): The Effect of IMF Programs on Economic Growth. Journal of Development Economics, 62 (2): 385-421.

Roman, M. - Popescu, M. E. (2014): The Effects of Training on Romanian Migrants' Income: A Propensity Score Matching Approach. Working Paper, No. 63251. University Library of Munich, Germany.

Rubin, D. B. - Thomas, N. (1996): Matching Using Estimated Propensity Scores: Relating Theory to Practice. Biometrics: 249-264.

Smith, J. A. - Todd, P. E. (2005): Does Matching Overcome LaLonde's Critique of Nonexperimental Estimators? Journal of Econometrics, 125(1): 305-353. 
Sturm, J. E. - Berger, H. - De Haan, J. (2005): Which Variables Explain Decisions on IMF Credit? An Extreme Bounds Analysis. Economics \& Politics, 17(2): 177-213.

Vreeland, J. R. (2002): The Effect of IMF Programs on Labor. World Development, 30(1): 121139.

Vreeland, J. R. (2004): Institutional Determinants of IMF Agreements. UCLA International Institute.

Vreeland, J. R. (2006): The International Monetary Fund (IMF): Politics of Conditional Lending. London - New York: Routledge. 